\title{
Air quality and seasonal variations in consultations for respiratory, allergic, dermatological and gastrointestinal diseases in Bahrain, 2007
}

\author{
R.R. Hamadeh ${ }^{7}$ and K.A. Al-Roomi ${ }^{7}$
}

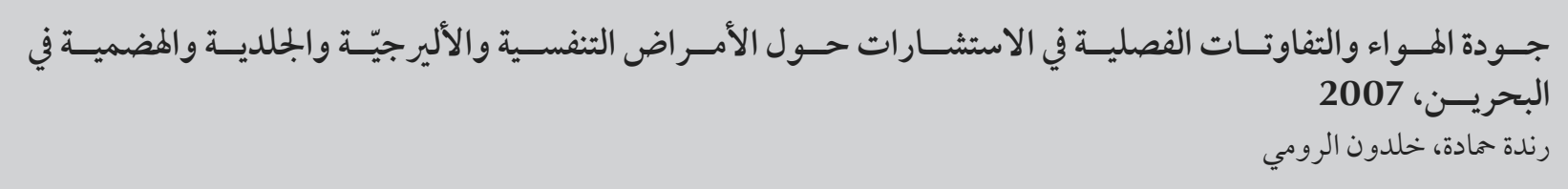

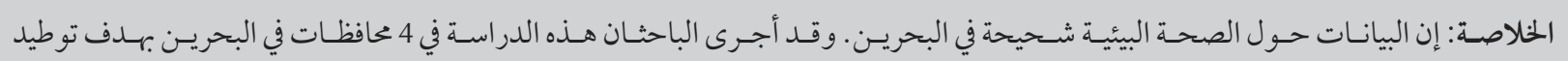

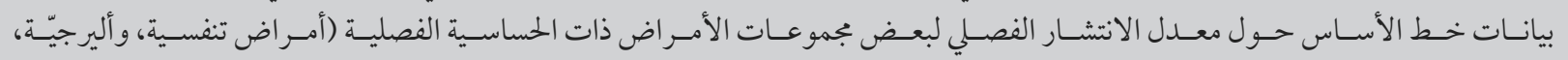

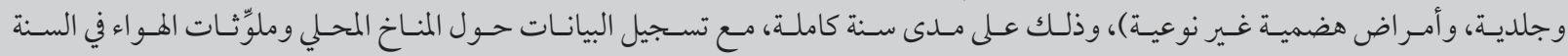

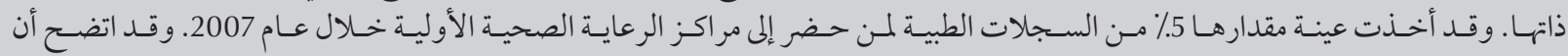

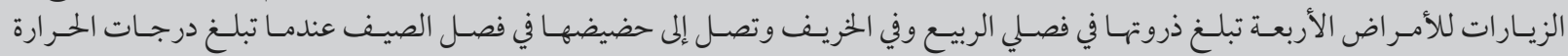

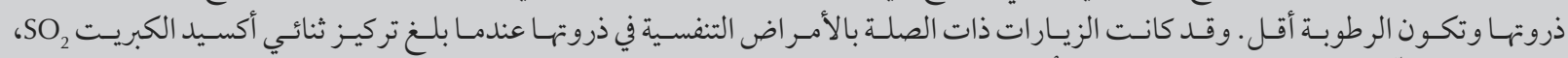

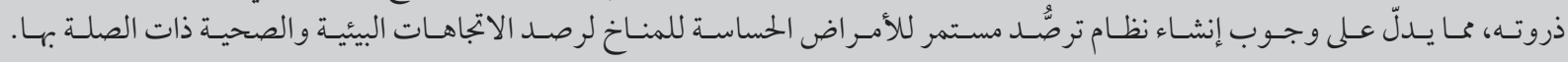

ABSTRACT Environmental health data in Bahrain are scarce. This study in 4 governorates of Bahrain aimed to establish baseline data on the seasonal prevalence of certain disease groups that are sensitive to climate (respiratory, allergic, dermatological and non-specific gastrointestinal diseases) over a 1-year period and to record local climate and air pollutant data for the same year. A 5\% sample of medical records for those who attended primary health-care centres during 2007 was taken. Visit rates for all 4 diseases had peaks, in spring and in autumn, with the lowest rates in the summer season when the average temperatures were highest and average humidity was lower. Respiratory-related visits were highest when the air concentrations of $\mathrm{SO}_{2}$ were highest. An ongoing surveillance system for climate-sensitive diseases should be initiated to monitor and relate health and environmental trends.

Qualité de l'air et variations saisonnières dans des consultations pour des maladies respiratoires, allergiques, dermatologiques et gastrointestinales à Bahreïn en 2007

RÉSUMÉ Les données sur la salubrité de l'environnement sont rares à Bahreïn. La présente étude menée dans quatre gouvernorats de Bahreïn visait à recueillir des données initiales sur la prévalence saisonnière de certains groupes de maladies qui sont sensibles au climat (maladies respiratoires, allergiques, dermatologiques et troubles gastrointestinaux non spécifiques) sur une période d'un an et à enregistrer les données sur le climat local et les polluants atmosphériques pour la même année. Un échantillon de $5 \%$ des dossiers médicaux des patients ayant consulté dans des centres de soins de santé primaires en 2007 a été sélectionné. Les fréquences de consultation pour les quatre groupes de maladies avaient des pics, au printemps et en automne, et des creux pendant la saison d'été, lorsque les températures moyennes étaint les plus élevées et que le taux d'humidité était le plus faible. Les consultations pour un motif respiratoire étaient plus nombreuses lorsque la concentration atmosphérique en dioxyde de soufre était la plus élevée. Un système de surveillance permanent pour les maladies sensibles au climat devrait être instauré pour surveiller et corréler les tendances sanitaires et environnementales. 


\section{Introduction}

Climate change is increasingly seen as a threat to public health, and climatesensitive diseases are predicted to be a major component of the future global burden of disease and premature death $[1-3]$. There is accumulating evidence of the growing vulnerability of humans due to the global climate changes and the critical challenges that the world would continue to face [4-8]. Diseases that are sensitive to climate and that could be affected by global climate changes include vector-borne diseases [9] and heat-related mortality [10], malnutrition [4], allergies [11], infectious diseases [9] and diarrhoeal diseases $[1,12]$. The percentage of global disability-adjusted life years due to climate-sensitive diseases in 2004 was estimated to be $0.4 \%$ [6].

A recent study of temporal trends in air temperatures in Bahrain showed a significant warming of the dry season temperatures between 1947 and 2005. Moreover, the overall rate of warming in the dry season during the day was 7 times that during the night and the trends were statistically significant for the months of May to July and October [13]. Furthermore, in a survey of country-specific environmental impact Bahrain was the 7 th worse-ranked country by proportional environmental impact among the 20 worst countries [14].

Data about environmental health in Bahrain are scarce, although the latest available data indicate that the current environmental health burden of disease is low [15]. Seasonal variation in the mortality rates in Bahrain was reported since the 1970s, showing more deaths in the winter season [16]. Badawi and Al Hoda stated that a mean average number of 4.6 patients per day were admitted to the emergency department at the Salmanyia Medical Complex when the mean average heat index was $69^{\circ} \mathrm{C}$ and 2.4 patients per day when it was $54{ }^{\circ} \mathrm{C}$ [17]. Husain and Chaudhary in their human health risk assessment on global warming in the Arab Gulf countries have reported that there is an anticipated increase in mortality rates due to cardiovascular diseases, respiratory diseases, thermal stress and infectious vector-borne illnesses between 2070 and 2099 [18]. In Bahrain, the projected excess mortality increases would be 39.2 per 1000 population, with substantial increases in the adjusted all-cause disability adjusted life years due to temperature rises in 2100 .

This study in Bahrain aimed to establish baseline data on the seasonal prevalence of certain disease groups that are sensitive to climate. The specific objectives were to determine the rate of consultations for respiratory, allergic, dermatological and non-specific gastrointestinal diseases among patients attending health centres in different governorates of Bahrain over a 1-year period and to record seasonal variations in local temperature, humidity and air pollutant levels in the same year.

\section{Methods}

\section{Study setting and sample}

The Ministry of Health In Bahrain provides primary health care services through 24 general health centres and 2 clinics, distributed in the 5 governorates. All the health centres are served by board-certified family physicians and offer curative and mother and child care services but vary in the provision of additional services such as radiology, physiotherapy and social and health education [19].

In 2008 a retrospective crosssectional study was conducted of the medical records of people who attended the health centres during 2007. The inclusion criteria for health centres were those that served a population of $>$ 30000 [20]. Thus, all the eligible health centres from the Capital, Northern, Muharraq and Central Governorates were included in the sampling frame, except for 1 health centre that served only labourers [16]. The Southern Governorate was excluded as it only had 2 clinics which did not satisfy the inclusion criteria. One health centre was selected from each of the 4 included governorates: Ibn Sina, Hamad Town, National Bank of Bahrain (NBB) and Sitra (representing Capital, Northern, Muharraq and Central Governorates respectively).

All people registered at the above health centres before 1 January 2007, who sought medical services during 2007, and whose family folders were available at the time of study, were included in the study. Those persons who visited the health centres for screening services (childhood, preschool and premarital), postnatal and antenatal visits, dental visits, visits for pregnancy tests and vaccinations were excluded. The sampling frame comprised all the family folders in the 4 health centres. Due to the large population size, a 5\% sample of the medical files was selected from each health centre, proportional to the latest available number of active files. Thus, from the total number of files in Ibn Sina (3296), NBB (6930), Sitra (8355) and Hamad Town (6100) samples of 165, 347, 418 and 305 family folders respectively were selected. A systematic sampling method was employed whereby a random number was picked to select the required number of files.

\section{Data collection}

A structured proforma was developed for data collection. It sought information on patients' demographic data, total number of visits and number of visits for specific disease categories that were sensitive to climate. These were: respiratory diseases (upper respiratory tract infections, asthma, emphysema, bronchitis); allergic diseases (allergic rhinitis and conjunctivitis); dermatological diseases (diaper rash, eczema, atopic dermatitis); and gastroenteritis. The diseases groups were identified from the literature [4] and reconfirmed 
by a panel of experts comprising family and community medicine consultants

The average monthly air temperature and humidity values in each of governorates were obtained from the Central Informatics Organization and Civil Aviation Affairs in Bahrain [21,22]. The months were categorized into 4 seasons: winter (December-February), spring (March-May), summer (JuneAugust), and autumn (SeptemberNovember) according to the Bahrain meteorological classification.

The average annual levels of selected air pollutants in each of governorates during 2007 were obtained from the Environmental Control Directorate: sulfur dioxide $\left(\mathrm{SO}_{2}\right)$, nitrogen dioxide $\left(\mathrm{NO}_{2}\right)$, carbon monoxide (CO), ozone $\left(\mathrm{O}_{3}\right)$, particulate matter with diameter $\leq 10 \mu \mathrm{m}\left(\mathrm{PM}_{10}\right)$ and $\leq 2.5 \mu \mathrm{m}\left(\mathrm{PM}_{2.5}\right)$ [Environmental Control Directorate,
Ministry of Industry and Commerce, Bahrain, personal communication, 2008).

\section{Data analysis}

The data was entered and analysed using SPSS program, version 17.0. Age-adjusted prevalence rates of the disease groups for each health centre were standardized to the total population in the sample. The $95 \%$ confidence intervals (CI) were computed for the mean rates. The chi-squared test and analysis of variance were applied.

\section{Results}

\section{Background characteristics of study sample \& health centres}

During the study period 4927 patients made a total number of 7592 visits (Ibn
Sina 1408, Hamad Town 2272, NBB 2250 and Sitra 1662). Table 1 shows the sociodemographic characteristics of the study patients by health centre. The highest proportion of patients was in the age group $\leq 10$ years $(19.2 \%)$ and the lowest in age $\geq 60$ years $(6.7 \%)$. More than half $(57.5 \%)$ of the study sample were never married and the majority (86.5\%) were Bahraini citizens. There were statistically significant variations across the health centres in the distribution of age $(P<0.001)$, marital status $(P$ $=0.020)$ and nationality $(P<0.001)$. The highest proportion of Bahraini nationals was in Sitra (97.7\%) and the lowest in Ibn Sina (47.4\%).

\section{Consultation rates for the studied diseases}

Respiratory diseases comprised the highest proportion of consultations for

\begin{tabular}{|c|c|c|c|c|c|c|c|c|c|c|c|}
\hline \multirow[t]{2}{*}{ Variable } & \multicolumn{2}{|c|}{$\begin{array}{l}\text { Ibn Sina } \\
\text { (Capital) }\end{array}$} & \multicolumn{2}{|c|}{$\begin{array}{l}\text { Hamad Town } \\
\text { (Northern) }\end{array}$} & \multicolumn{2}{|c|}{$\begin{array}{c}\text { NBB } \\
\text { (Muharraq) }\end{array}$} & \multicolumn{2}{|c|}{$\begin{array}{c}\text { Sitra } \\
\text { (Central) }\end{array}$} & \multicolumn{2}{|c|}{ Total } & \multirow[t]{2}{*}{$P$-value } \\
\hline & No. & $\%$ & No. & $\%$ & No. & $\%$ & No. & $\%$ & No. & $\%$ & \\
\hline Sex & & & & & & & & & & & 0.336 \\
\hline Male & 332 & 45.5 & 714 & 49.6 & 706 & 48.7 & 632 & 48.4 & 2384 & 48.4 & \\
\hline Female & 398 & 54.5 & 725 & 50.4 & 745 & 51.3 & 675 & 51.6 & 2543 & 51.6 & \\
\hline Total & 730 & 100.0 & 1439 & 100.0 & 1451 & 100.0 & 1307 & 100.0 & 4927 & 100.0 & \\
\hline Nationality & & & & & & & & & & & $<0.0001$ \\
\hline Bahraini & 346 & 47.4 & 1403 & 97.6 & 1237 & 85.3 & 1277 & 97.7 & 4263 & 86.5 & \\
\hline Other & 384 & 52.6 & 35 & 2.4 & 214 & 14.7 & 30 & 2.3 & 663 & 13.5 & \\
\hline Total & 730 & 100.0 & 1438 & 100.0 & 1451 & 100.0 & 1307 & 100.0 & 4926 & 100.0 & \\
\hline Marital status & & & & & & & & & & & 0.020 \\
\hline Never married & 412 & 56.4 & 876 & 60.9 & 804 & 55.4 & 743 & 56.8 & 2835 & 57.5 & \\
\hline Ever married & 318 & 43.6 & 563 & 39.1 & 647 & 44.6 & 564 & 43.2 & 2092 & 42.5 & \\
\hline Total & 730 & 100.0 & 1439 & 100.0 & 1451 & 100.0 & 1307 & 100.0 & 4927 & 100.0 & \\
\hline Age (years) & & & & & & & & & & & $<0.0001$ \\
\hline$\leq 9$ & 164 & 22.7 & 255 & 18.3 & 241 & 16.7 & 267 & 21.0 & 927 & 19.2 & \\
\hline 10-19 & 91 & 12.6 & 344 & 24.7 & 266 & 18.5 & 173 & 13.6 & 874 & 18.1 & \\
\hline $20--29$ & 101 & 14.0 & 279 & 20.0 & 225 & 15.6 & 289 & 22.7 & 894 & 18.5 & \\
\hline 30-39 & 147 & 20.4 & 136 & 9.7 & 237 & 16.5 & 253 & 19.9 & 773 & 16.0 & \\
\hline $40-49$ & 115 & 15.9 & 212 & 15.2 & 230 & 16.0 & 133 & 10.5 & 690 & 14.3 & \\
\hline 50-59 & 52 & 7.2 & 127 & 9.1 & 107 & 7.4 & 62 & 4.9 & 348 & 7.2 & \\
\hline$\geq 60$ & 52 & 7.2 & 42 & 3.0 & 134 & 9.3 & 94 & 7.4 & 322 & 6.7 & \\
\hline Total & 722 & 100.0 & 1395 & 100.0 & 1440 & 100.0 & 1271 & 100.0 & 4828 & 100.0 & \\
\hline
\end{tabular}

$N B B=$ National Bank of Bahrain 
the 4 disease groups studied (187 per 1000 visits) followed by gastrointestinal diseases (27 per 1000 visits), allergies (16 per 1000 visits) and dermatological diseases (7 per 1000 visits) (Figure 1). Among the health centres Ibn Sina had the highest rates of visits for respiratory (279 per 1000), allergic diseases (18 per 1000) and dermatological diseases (11 per 1000) (Figure 1). NBB had the highest rate of non-specific gastrointestinal diseases (15.6\%) (32 per 1000). These differences between health centres were statistically significant $(P<$ 0.001 ) for respiratory diseases but not for the other disease categories.

\section{Seasonal consultation rates}

Figure 2 shows the rates for all health centres combined for each of the 4 disease groups together with the average temperatures in Bahrain during the 4 seasons. Visit rates for respiratory diseases had 2 peaks, 1 in spring and 1 in autumn, with the lowest rates in the summer season. The seasonal distribution of allergic- and dermatological-related visits had a peak around the spring season. The gastrointestinal diseaserelated visits were lowest in summer and highest in spring.

The seasonal pattern was consistent across all health centres except for Sitra. Ibn Sina health centre had the highest rate of visits for respiratory diseases throughout the seasons (Figure 3). In NBB there were 2 peaks in the rate of respiratory-related visits (335 per 1000 visits in autumn, 295 per 1000 in winter, 273 per 1000 in spring, and 213 per 1000 in summer). The seasonal distribution of allergic- and dermatologicalrelated visits followed a similar pattern in all the 4 health centres (Table 2). Rates were highest for the former in Ibn Sina and for the latter in NBB. NBB health centre had the highest rates of gastrointestinal disease-related visits in winter and spring.

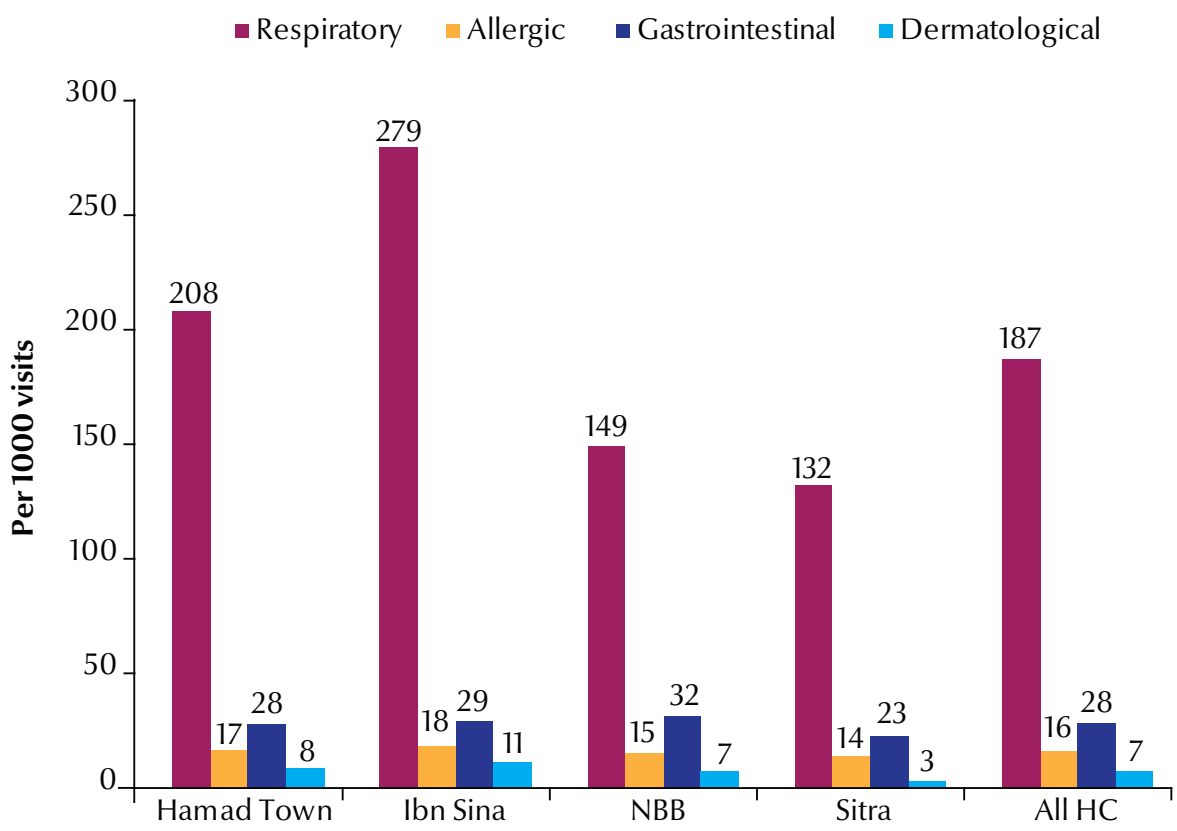

Figure 1 Total consultation rates for respiratory, allergic, dermatological and gastrointestinal diseases per 1000 visits in all studied health centres $(\mathrm{HC})$ in Bahrain, 2007 (NBB = National Bank of Bahrain)

Respiratory $\square$ Gastrointestinal $\square$ Allergic $\square$ Dermatological

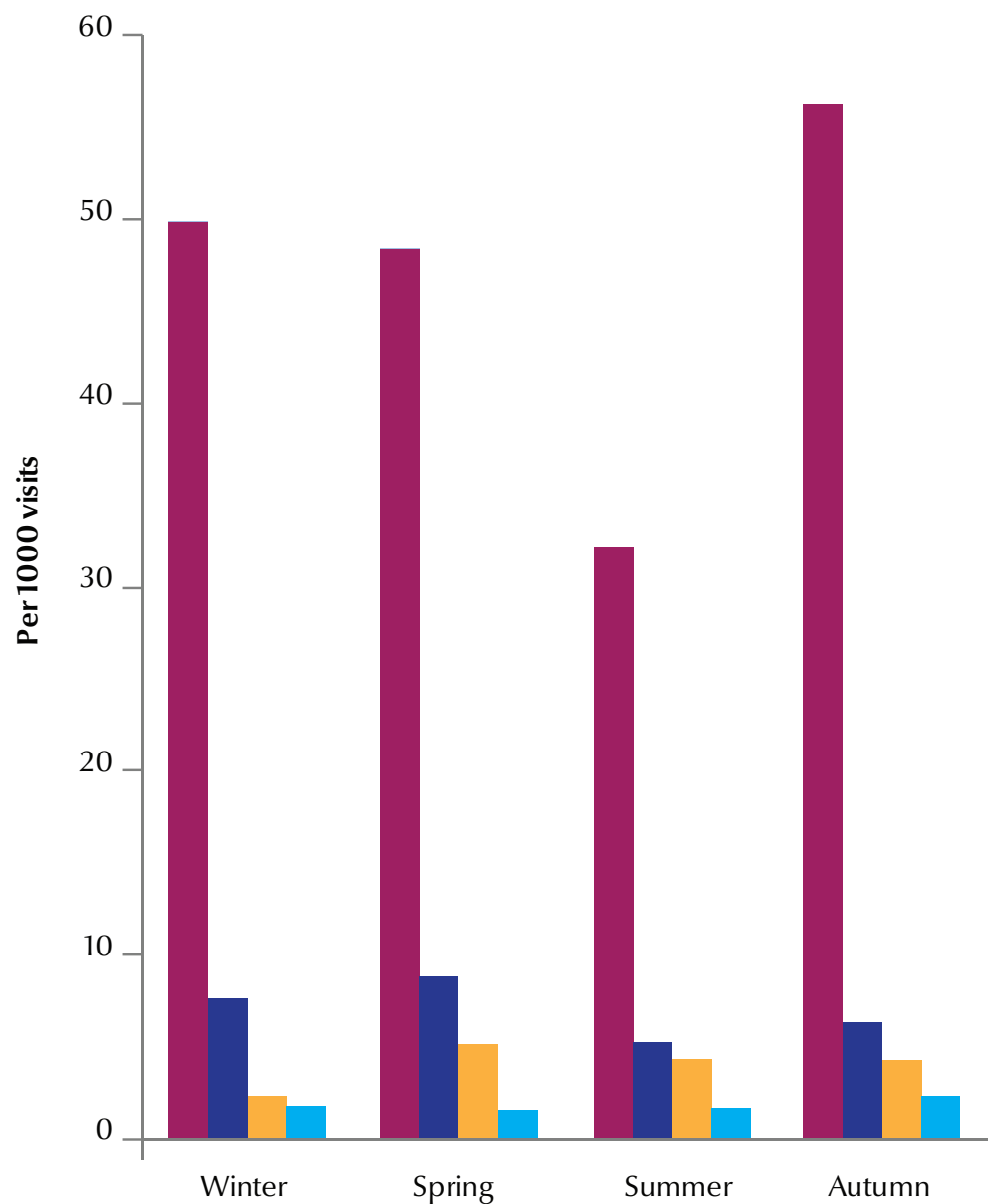

Figure 2 Seasonal variation of total consultation rates for respiratory, allergic, dermatological and gastrointestinal diseases per 1000 visits in all studied health centres in Bahrain, 2007 


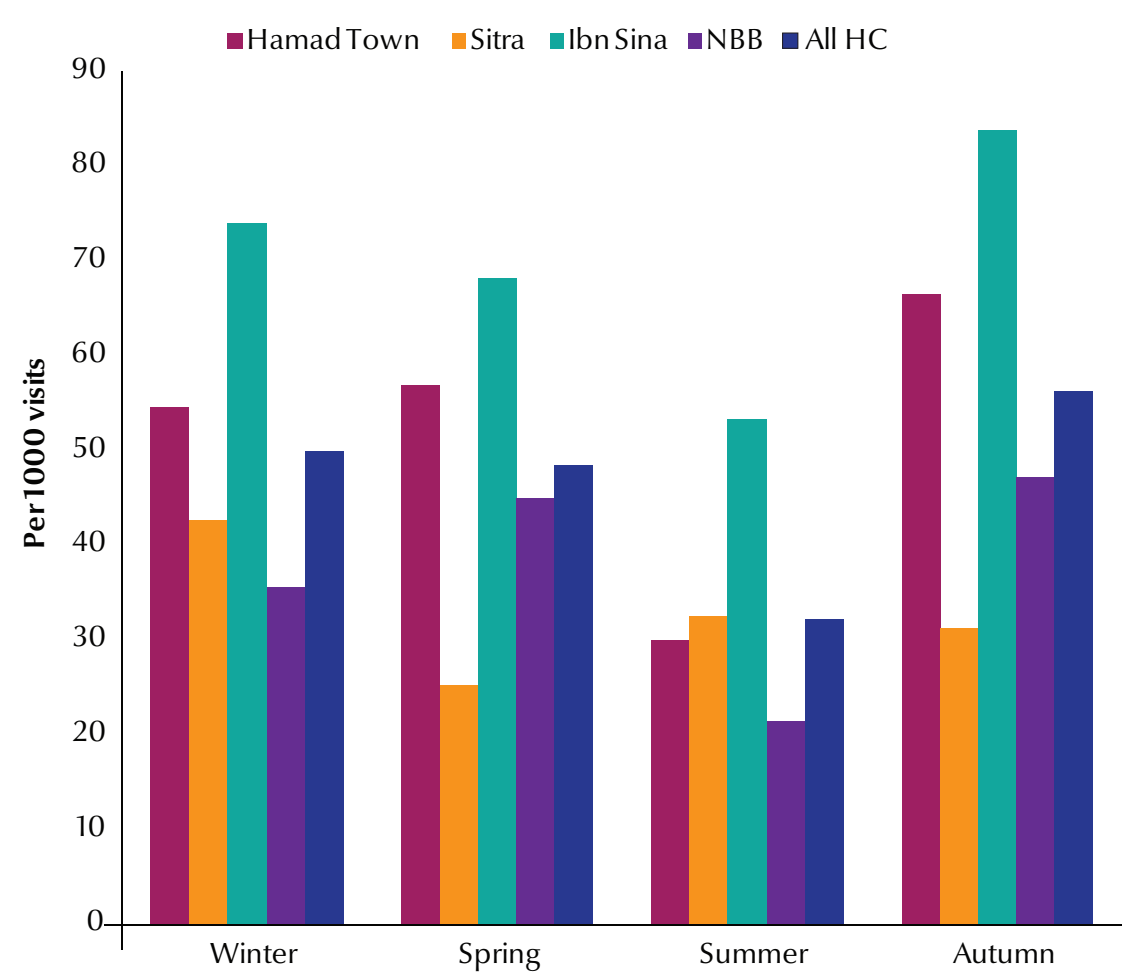

Figure 3 Seasonal rate of consultations for respiratory diseases per 1000 visits in the studied health centres (HC) in Bahrain, 2007 (NBB = National Bank of Bahrain)

\section{Seasonal climate and pollutant levels}

Table 3 presents the average annual air levels of $\mathrm{SO}_{2}, \mathrm{NO}_{2}, \mathrm{CO}, \mathrm{O}_{3}, \mathrm{PM}_{10}$ and $\mathrm{PM}_{2.5}$ recorded in the governorates where the health centres are located. The $\mathrm{SO}_{2}$ hourly average concentrations were highest in Northern Governorate (where Hamad Town health centre is located) and lowest in Muharraq Governorate (where NBB health centre is located). The $\mathrm{NO}_{2}$ hourly average concentrations were highest during spring in all 4 governorates, while Central Governorate (where Sitra health centre is located) had the highest throughout the year. The CO hourly average concentrations were highest in Capital Governorate (where Ibn Sina health centre is located). There was no variation in the 24-hour average $\mathrm{PM}_{2.5}$ concentrations except for a peak in Muharraq Governorate (where NBB health centre is located). Figure 4 plots the seasonal hourly average levels of $\mathrm{SO}_{2}$. None of the other studied pollutants showed any variation by season and consultation visits.

The average temperature and humidity in Bahrain over the 4 seasons in 2007 are shown in Figure 5.

\section{Discussion}

There is substantial evidence from the existing literature indicating that climate impacts human health, and it is hypothesized that global and local climate changes will have an impact in the future health of population worldwide [1]. Although the health effects of climate change have attracted attention worldwide, such a concern is not fully appreciated in Bahrain, partly due to the lack of environmental and epidemiological data. In addition, this issue does not appear to be on the high priority list of the political and health agenda.

There were seasonal variations in the pattern of consultations for respiratory diseases, with the highest rates occurring in autumn and the lowest in summer and an inverse relationship observed between average temperature and the consultation rates. The consultation rate was lowest in summer, when the average temperatures were highest and average humidity levels were lowest. Our findings are in line with other evidence that Middle Eastern populations suffer from respiratory illnesses related to weather conditions [23]. The consultation rates for the 3 other disease categories (allergic, dermatological and gastrointestinal) did not follow a seasonal pattern of variation which may be due to their low consultation rates. Since Bahrain has a warm climate with high temperatures and humidity during most of the year, high transmission of certain diseases through air, contaminated food and water are expected. In addition, conditions that are directly or indirectly related to thermal stress are expected to rise, particularly among vulnerable groups such as children and elderly people [8]. This calls for adequate responses such as establishing an online notification system for illnesses that may be climate sensitive.

There also appeared to be a relationship between the levels of some pollutants and the occurrence of respiratory diseases. When the concentrations of $\mathrm{SO}_{2}$ were highest, the rates of respiratory-related visits were highest as well. Furthermore, there were differences between the health centres, with Ibn Sina having the highest morbidity rates from respiratory-related diseases. The concentrations of $\mathrm{SO}_{2}$ followed a similar pattern to those of consultations for respiratory illnesses. Moreover, the $\mathrm{SO}_{2}$ as well as $\mathrm{CO}$ levels were high in the regions with highest rates of visits attributed to respiratory conditions. However, the other pollutants did not show such a pattern.

The prevalence of the 4 studied disease groups was greatest among those below the age of 10 years (35.3\%). Furthermore, over half of the visits of the preschool age children 


\begin{tabular}{|c|c|c|c|c|}
\hline \multirow[t]{2}{*}{ Disease category/season } & \multicolumn{4}{|c|}{ Consultation rate per 1000 visits } \\
\hline & $\begin{array}{l}\text { Ibn Sina } \\
\text { (Capital) }\end{array}$ & $\begin{array}{l}\text { Hamad Town } \\
\text { (Northern) }\end{array}$ & $\begin{array}{c}\text { NBB } \\
\text { (Muharraq) }\end{array}$ & $\begin{array}{c}\text { Sitra } \\
\text { (Central) }\end{array}$ \\
\hline \multicolumn{5}{|l|}{ Respiratory diseases } \\
\hline Winter & 74 & 55 & 36 & 43 \\
\hline Spring & 68 & 57 & 45 & 25 \\
\hline Summer & 53 & 30 & 21 & 32 \\
\hline Autumn & 84 & 66 & 47 & 31 \\
\hline All seasons & 279 & 208 & 149 & 131 \\
\hline \multicolumn{5}{|l|}{ Gastrointestinal diseases } \\
\hline Winter & 9 & 7 & 10 & 5 \\
\hline Spring & 8 & 8 & 10 & 9 \\
\hline Summer & 7 & 4 & 4 & 6 \\
\hline Autumn & 6 & 9 & 7 & 2 \\
\hline All seasons & 30 & 28 & 31 & 22 \\
\hline \multicolumn{5}{|l|}{ Allergic diseases } \\
\hline Winter & 1 & 1 & 4 & 3 \\
\hline Spring & 9 & 5 & 4 & 4 \\
\hline Summer & 5 & 4 & 4 & 4 \\
\hline Autumn & 4 & 7 & 3 & 3 \\
\hline All seasons & 19 & 17 & 15 & 14 \\
\hline \multicolumn{5}{|l|}{ Dermatological diseases } \\
\hline Winter & 2 & 1 & 3 & 1 \\
\hline Spring & 2 & 1 & 3 & 0 \\
\hline Summer & 2 & 3 & 0 & 2 \\
\hline Autumn & 5 & 3 & 1 & 1 \\
\hline All seasons & 11 & 8 & 7 & 4 \\
\hline
\end{tabular}

$N B B=$ National Bank of Bahrain

were in these 4 disease categories. The literature indicates that children are vulnerable to changes in temperature and at a higher risk of morbidity and mortality [24]. Children, particularly the very young, have a naive immune system, making them more vulnerable to infectious diseases such as gastrointestinal diseases, respiratory diseases, malaria and parasitic infections. Furthermore, the incidence of fever, electrolyte imbalance and renal diseases increases among children during heat waves [24].

Designing studies to test hypotheses about the possible relationship between climate changes and disease occurrence are difficult to conduct and encounter limitations. The main limitations of the current study were that data were obtained from medical records, in which information might have been influenced by the doctors' recording practices. However, if this assumption

\begin{tabular}{lccccc}
\hline Table 3 Average annual air pollutant concentrations in the 4 studied governorates in Bahrain, 2007 \\
\hline \multicolumn{7}{l}{ Pollutant } & Capital & Annual average pollutant concentrations & Northern & Muharraq & Central & P-value \\
& 8.2 & 9.0 & 4.6 & 6.4 & $<0.001$ \\
$\mathrm{SO}_{2}(\mathrm{ppb})$ & 21.5 & 15.3 & 18.5 & 23.4 & 0.057 \\
$\mathrm{NO}_{2}(\mathrm{ppb})$ & 0.51 & 0.40 & 0.41 & 0.37 & 0.493 \\
$\mathrm{CO}(\mathrm{ppm})$ & 37.5 & 56.3 & 65.3 & 38.2 & 0.001 \\
$\mathrm{O}_{3}(\mathrm{ppb})$ & 145.4 & 145.7 & 155.3 & 193.1 & 0.629 \\
$\mathrm{PM}_{10}\left(\mu \mathrm{g} / \mathrm{m}^{3}\right)$ & 49.7 & 52.3 & 55.3 & 56.9 & 0.929 \\
$\mathrm{PM}_{2.5}\left(\mu \mathrm{g} / \mathrm{m}^{3}\right)$ & & &
\end{tabular}

$\mathrm{SO}_{2}=$ sulfur dioxide; $\mathrm{NO}_{2}=$ nitrogen dioxide; $\mathrm{CO}=$ carbon monoxide; $\mathrm{O}_{3}=$ ozone; $P M_{10}=$ particulate matter with diameter $\leq 10 \mu \mathrm{m} ; \mathrm{PM} \mathrm{L}_{2.5}=$ particulate matter with diameter $\leq 2.5 \mu \mathrm{m}$. 


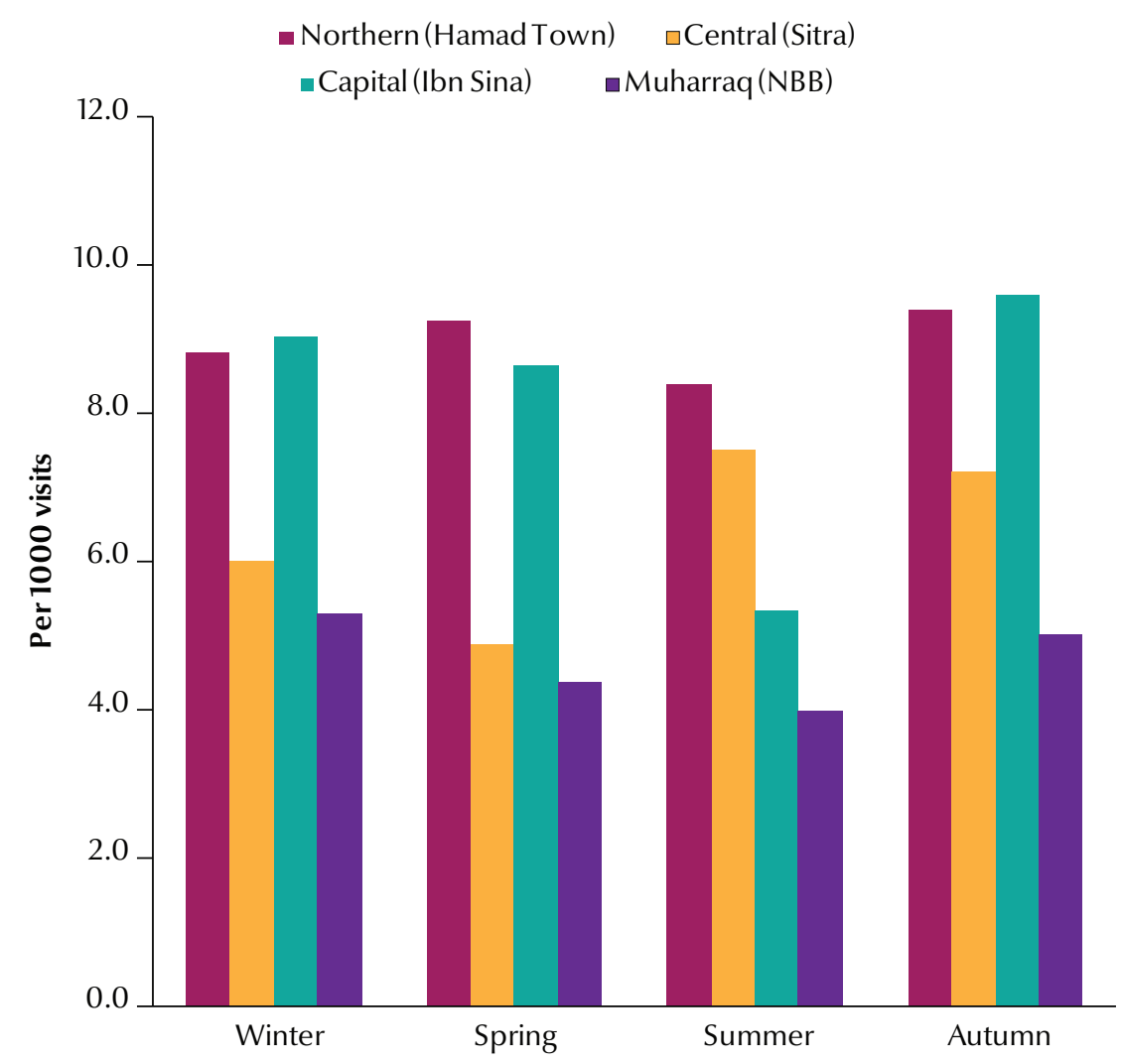

Figure 4 Seasonal average air concentrations of sulfur dioxide $\left(\mathrm{SO}_{2}\right)$ in the 4 studied governorates of Bahrain, 2007 (NBB = National Bank of Bahrain)

were true it would have resulted in under-reporting of diseases. Moreover, having qualified family physicians serving in all the health centres in Bahrain would make misdiagnosis unlikely. Secondly, the rationale of the study assumed that the subjects' exposures to

pollutants were mainly based on their area of residence and therefore data were collected from the local health centres. It is plausible that some of the working population were exposed to different levels of pollutants in their work locations. However, subjects who

were not in the main workforce age accounted for around two-thirds of the total population. Thus, such limitations were unlikely to have affected the overall direction of the results

In view of the information gap related to climate change and health in Bahrain, the first step to rectify this situation would be to establish an integrated network for environmental and epidemiological data. This requires the collaboration of the Ministry of Health with the Environmental Control Directorate and Ministry of Industry and Commerce. An ongoing surveillance system should be initiated to monitor and correlate health and environmental trends in the country. This network would also establish a link between the epidemiologic surveillance system at the Public Health Directorate and the meteorological data for prompt action by policy-makers.

\section{Conclusions}

Due to the paucity of research on the adverse health effects of climate on health in Bahrain, research should be encouraged to determine the burden of climate-sensitive diseases in the country to enable policy-makers to take action.

\section{Acknowledgements}

This study is based on the project of the Assessment of the Vulnerability of Human Health to Climate Change in the Kingdom of Bahrain Report, Bahrain's Second National Communication under the United Nations Framework Convention on Climate Change, 2012.

Special thanks are due to the medical students in the College of Medicine and Medical Sciences, Arabian Gulf University who participated in data collection.

Competing interests: None declared 


\section{References}

1. Contribution of Working Group II to the fourth assessment report of the Intergovernmental Panel on Climate Change, 2007. Cambridge, United Kingdom, Cambridge University Press; 2007 (http://www.ipcc.ch/publications_and_data/ar4/wg2/en/ contents.html, accessed 11 March 2014).

2. Costello A, Abbas M, Allen A, Ball S, Bell S, Bellamy R, et al. Managing the health effects of climate change: Lancet and University College London Institute for Global Health Commission. Lancet, 2009, 373(9676):1693-1733.

3. Atlas of health and climate. Geneva, World Health Organization and World Meteorological Organization, 2012 (http://www. who.int/globalchange/publications/atlas/report/en/index. html, accessed 11 March 2014).

4. McMichael AJ et al., eds. Climate change and human health. Risks and responses. Geneva, World Health Organization, 2003.

5. McMichael AJ et al. Climate change: a time of need and opportunity for the health sector. Lancet, 2009, 374(9707):2123-2125.

6. Protecting health from climate change. Connecting science, policy and people. Geneva, World Health Organization, 2009.

7. Cheng Y, Kan H. Effect of the interaction between outdoor air pollution and extreme temperature on daily mortality in Shanghai, China. Journal of Epidemiology, 2012, 22(1):28-36.

8. Global health risks. Mortality and burden of disease attributable to selected risk factors. Geneva, World Health Organization, 2009.

9. Semenza JC, Menne B. Climate change and infectious diseases in Europe. Lancet Infectious Diseases, 2009, 9(6):365-375.

10. McMichael AJ et al. International study of temperature, heat and urban mortality: the 'ISOTHURM' project. International Journal of Epidemiology, 2008, 37(5):1121-1131.

11. D'Amato G, Cecchi L. Effects of climate change on environmental factors in respiratory allergic diseases. Clinical \& Experimental Allergy, 2008, 38(8):1264-1274.

12. Hall GV, D'Souza RM, Kirk MD. Foodborne disease in the new millennium: out of the frying pan and into the fire? Medical Journal of Australia, 2002, 177(11-12):614-618.
13. Elagib NA, Abdu ASA. Development of temperatures in the Kingdom of Bahrain from 1947 to 2005. Theoretical and Applied Climatology, 2009, DOI 10.1007/S00704-009-0205-y.

14. Bradshaw CJA, Giam X, Sodhi NS. Evaluating the relative environmental impact of countries. PLoS One. 2010;5(5):e10440. 10.1371/journal.pone.0010440 PMID:20454670

15. Environmental burden of disease country profiles. Public health and environment. Geneva, World Health Organization, 2007 (http://www.who.int/quantifying_ehimpacts/national/ countryprofile/intro/en/index.html, accessed 11 March 2014).

16. Husain T, Chaudhary JR. Human health risk assessment due to global warming-a case study of the Gulf countries. International Journal of Environmental Research and Public Health 2008, 5(4):204-212.

17. Armenian $\mathrm{HK}$ et al. Seasonal variation of hospital deaths in some Middle Eastern countries. Lebanese Science Bulletin, 1988, 4(2):55-64

18. Badawi NK, Al Hoda M. Environmental factors and heat-related illness. Middle East Journal of Emergency Medicine, 2004, 4(2): oral abstract presentation \#42.

19. Health centers [Internet]. Manama, Bahrain: Ministry of Health (http://www.moh.gov.bh/EN/MOHServices/Services/OurPrimaryServices/HealthCenter.aspx, accessed 11 March 2014).

20. Health statistics, 2007. Manama, Bahrain, Ministry of Health, Health Information Directorate, 2008.

21. Statistics. Area and meteorological conditions. Manama, Bahrain, Central Informatics Organization, 2007.

22. 1991-2008 statistics. Manama, Bahrain: Civil Aviation Affairs, Directorate of Meteorology and Climatology Section, 2008.

23. Waness A et al. Respiratory disorders in the Middle East: a review. Respirology, 2011, 16(5):755-766.

24. Xu Z et al. Impact of ambient temperature on children's health: a systematic review. Environmental Research, 2012, 117:120-131. 